ção. Adenomegálias submandibulares e cervicais, dolorosas à palpação. No próprio dia, faz-se biópsia incisional da lesão. Resultado anatomopatológico: 'Carcinoma pavimentocelular bem diferenciado, queratinizado e com áreas de ulceração. Lesão interessa as margens (R1)." Estudo imunohistoquímico: P16 negativa. Sugeriu-se realizar, numa primeira fase, ecografia cervical e da tiroide. Infelizmente, o doente recusou o estadiamento. Discussão e conclusões: O cancro oral ocorre, geralmente, em área que se diria acessível ao observador externo e até ao próprio doente. No entanto é facto conhecido que, uma parte relevante destas neoplasias são diagnosticadas em estádio avançado, com subsequente impacto negativo na sobrevida. Nos estádios precoces do cancro oral a cirurgia é resolutiva e o prognóstico favorável. A quimioradioterapia adjuvante poderá estar indicada. Geralmente a quimioradioterapia isolada está reservada para doentes com tumores irressecáveis. A localização da lesão, apesar de menos frequente, é acessível ao observador sugerindo que o doente não tem cuidados dentários regulares. Também nos parece improvável o tempo de evolução apontado. O doente optou por gerir a sua doença em Moçambique pelo que lhe foi fornecida toda a informação clínica.

http://doi.org/10.24873/j.rpemd.2022.01.873

\section{\#014 Fibromatose gengival hereditária - A propósito de um caso clínico}

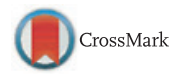

Luísa Figueiredo, José Bastos Ferrão*, Catarina Machado Ferreira, Ana Fernandes

Centro Hospitalar e Universitário Lisboa Central - Hospital de S. José, Centro Hospitalar e Universitário Lisboa Central - Hospital D. Estefania.

Introdução: A fibromatose gengival hereditária ou elefantiase gengival caracteriza-se por um crescimento lento, progressivo e benigno dos tecidos gengivais. Estes apresentam coloração normal, consistência firme, sem sinais inflamatórios. Pode aparecer na forma isolada ou englobado numa síndrome. As caraterísticas mais frequentemente associadas são a hipertricose, a perturbação do desenvolvimento intelectual e a epilepsia. Pode causar problemas estéticos e funcionais, entre os quais, a dificuldade na fonação, dor por traumatismo do tecido gengival, atraso na erupção, atraso da esfoliação dos dentes decíduos, diastemas e alterações da oclusão. O risco de cárie aumenta, por dificuldade no controlo da placa bacteriana. A etiologia tem uma componente hereditária, com transmissão, fundamentalmente, autossómica dominante. Estudos genéticos determinaram uma condição geneticamente heterogénea. Atualmente conhecem-se quatro loci associados à forma isolada de fibromatose gengival hereditária: dois no cromossoma 2 (GINGF no 2p21-22 e GINGF3 no 2p22.3-p23.3), um no cromossoma 5 (GINGF2 no 5q13-q22) e outro no cromossoma 11 (GINGF4 no cromossoma 11p15). Descrição do caso clínico: Doente do sexo feminino, raça negra, 27 anos de idade, em seguimento neste Serviço. Apresenta aumento generalizado gengival, com expressão máxima ao nível dos $2 .^{\circ}, 3 .^{\circ}$ e $4 .^{\circ}$ quadrantes. Sem antecedentes pessoais patológicos, mas com história familiar idêntica (mãe e irmão). Realizou-se gengivectomia em 3 momentos, 1 por quadrante, no período de 6 meses. O exame histológico revelou: hiperplasia fibroepitelial da gengiva, paraqueratose do epitélio. Sem evidência de neoplasia. Pedimos a colaboração da especialidade de Genética, mas a doente não compareceu a nenhum dos 3 agendamentos efetuados e abandonou o seguimento em Estomatologia. Discussão e conclusões: O diagnóstico mais provável, face à história pessoal e familiar, é o de Fibromatose Gengival Hereditária. Apesar de terem sido excluídas outras causas de aumento do volume gengival a avaliação multidisciplinar, nomeadamente o despiste genético seria mandatório. A fibromatose gengival hereditária acarreta limitações estéticas e, em algumas situações, funcionais, mas é compatível com uma vida dentro dos padrões de normalidade. No caso clínico em apreço a melhoria do componente estético poderá ser a razão do desinteresse da doente no seguimento hospitalar.

http://doi.org/10.24873/j.rpemd.2022.01.874

\section{\#015 Abordagem do ameloblastoma multiquístico (1) CrossMark}

Pedro Dias Ferraz*, Beatriz Dominguez, João Mendes de Abreu, José Pedro Figueiredo

\section{Centro Hospitalar Universitário de Coimbra}

Introdução: O ameloblastoma é um tumor odontogénico que representa $1 \%$ de todos os tumores da cavidade oral. É um tumor benigno, que geralmente ocorre entre a terceira e quinta décadas de vida, com a mesma frequência em homens e mulheres, e a localização é de 80 \% na mandíbula. Os achados imagiológicos não são patognomónicos e a lesão deve ser confirmada com exame histológico. Descrição do caso clínico: É descrito o caso clínico de um doente de 45 nos que deu entrada no Serviço de Urgência de Estomatologia do CHUC. Referiu antecedentes pessoais de traumatismo da face por acidente de viação há mais de 10 anos. Ao exame objetivo, apresentava tumefação mandibular à esquerda, associado a abaulamento do fundo vestibular em relação com os dentes 33 e 35. À realização da ortopantomografia, observou-se lesão radiolucente, assim como reabsorção radicular das raízes de dente 35 e 36. Devido à extensão da lesão e a sua proximidade com o nervo alveolar inferior foi efetuado um exame CBCT. Foi realizada enucleação da lesão seguida de curetagem cirúrgica. A biópsia excisional apresentava vários fragmentos membranáceos, sendo o de maior dimensões de 3,7 x 2,3 x 0,4 mm, O diagnóstico anatomopatológico definitivo revelou ameloblastoma multiquístico positivo para a mutação BRAF V600E. Foi realizado TC maxilo-facial para definir os limites de margens livres de lesão para uma nova abordagem cirúrgica, tendo sido reencaminhado para a consulta de cirurgia maxilo-facial. Discussão e conclusões: Os ameloblastomas são clinicamente classificados em três tipos: sólido e multicístico, unicístico. Atualmente, os ameloblastomas sólidos e multicísticos são considerados localmente agressivos, com altas taxas de recorrência entre os $60-80$ \% com o tratamento conservador. A cirurgia radical implica mandibulectomia marginal ou segmentar com necessidade de margens de $1 \mathrm{~cm}$, uma vez que células de ameloblastoma podem ser encontradas a $8 \mathrm{~mm}$ da 
margem radiológica e clínica do tumor. A taxa de recorrência em torno de 0-10\%, torna esta técnica a opção de eleição. A mutação BRAF V600E é a alteração genética mais comum no ameloblastoma, e sua frequência varia de $43 \%$ a $90 \%$. Alguns estudos corroboram a associação a desta mutação a maior risco de recorrência e a menor sobrevida. Por outro lado, estudo recentes, demonstram resposta promissora sob tratamento neoadjuvante com inibidores de BRAF.

http://doi.org/10.24873/j.rpemd.2022.01.875

\section{\#016 Excisão de hiperplasia fibrosa inflamatória com laser Er: YAG causada

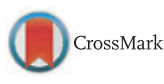

Pedro Dias Ferraz, João Manuel Santos Marques, Lúcia Ferraz, Américo Ferraz*

\section{LACLINIC SA}

Introdução: A epúlide fissurata é uma lesão resultante de uma reação hiperplásica do tecido conjuntivo fibroso e se desenvolve em associação com os limites de uma prótese total ou parcial mal ajustada. Apresenta-se como tecido hiperplásico no vestíbulo alveolar, com a mesma coloração da mucosa. Geralmente é uma massa firme e fibrosa, embora algumas lesões sejam eritematosas e ulceradas. O seu tamanho pode variar de $1 \mathrm{~cm}$ a lesões maiores (que envolvem grande parte do comprimento vestibular). Descrição do caso clínico: Doente de 55 anos, do sexo feminino, recorreu à consulta pela impossibilidade de uso da prótese de acrílico superior associada à dor. Ao exame objetivo, apresentava lesão fibrótica hiperplásica na crista vestibular do segundo quadrante, com aproximadamente 2,5 cm de diâmetro maior compatível com Epulide fissuratum Optou-se pela excisão da lesão com laser Erbium YAG. O procedimento foi realizado sob anestesia local. O modo Long Pulse (etapa 1) foi usado para fazer a ablação inicial da lesão logo acima do tecido adjacente. Usando os parâmetros de tratamento descritos não ocorreu qualquer hemorragia durante o procedimento. Numa segunda etapa, foi utilizado o modo Very Long Pulse para terminar a ablação até o nível do tecido adjacente. $\mathrm{O}$ efeito térmico dos pulsos do modo VLP coagula os vasos sanguíneos menores na área circundante, eliminando a hemorragia. A hemostasia proporcionada pelo laser reduz a formação de hematomas, contribuindo para uma recuperação mais confortável. Por fim (passo 3), utilizou-se a opção do laser de baixa energia através da peça Genova (Neodímio: YAG), para promover a aceleração da formação de colagénio e também a cicatrização pós-operatória. Logo após o término da cirurgia, a prótese de acrílico foi rebasada e a doente voltou para casa com a própria prótese colocada. Discussão e conclusões: Neste caso, foi realizada a excisão da lesão com laser de Erbium (Er:YAG) Lightwalker da Fotona. Esta forma de excisão resulta num pós-operatório indolor e conduz à cicatrização acelerada devido à ablação com laser Er:YAG, permitindo ao paciente colocar imediatamente a nova prótese adaptada ao novo vestíbulo. As técnicas convencionais incluem o uso de um bisturi, o que exigiria sutura. Isso teria levado a maior grau de desconforto pós-operatório e também à necessidade de retorno para retirar os pontos de sutura.

http://doi.org/10.24873/j.rpemd.2022.01.876
\#017 Pólipo fibro-epitelial (leaf-like fibroma) induzido por prótese: um caso clínico

Arturo López*, Frederico Gonçalves, João Mendes de Abreu, Sara Garrido, Sofia Correia, José Pedro Figueiredo

Serviço de Estomatologia - Centro Hospitalar e Universitário de Coimbra, Serviço de Cirurgia Maxilo-Facial - Centro Hospitalar e Universitário de Coimbra, Faculdade de Medicina da Universidade de Coimbra

Introdução: O pólipo fibroepitelial (ou leaf-like fibroma) induzido por prótese induzido por prótese é um tipo de hiperplasia fibrosa inflamatória pouco comum que ocorre no palato duro abaixo de uma prótese superior. Apresenta-se como uma massa plana rosada com bordos irregulares (lembrando uma folha) em íntima proximidade com o palato, assentando numa ligeira depressão, mas que é facilmente destacada revelando um pedículo estreito que a une ao palato. O seu tratamento é cirúrgico, sendo aconselhável o estudo anatómo-patológico da peça, e para evitar recorrências a prótese deve ser ajustada ou confecionada uma nova. Descrição do caso clínico: Mulher de 75 anos, referenciada à Consulta Externa por uma lesão a nível do palato duro com vários anos de evolução, provocando desconforto local recentemente. Ao exame objetivo apresentava uma lesão rosada, plana, de bordos irregulares com pequeno pedículo a conetá-la com o palato duro, por debaixo de prótese total superior. A prótese encontrava-se desajustada, não sendo revista em consulta há vários anos. Foi realizada uma biópsia excisional da lesão cujo estudo anátomo-patológico mostrou tratar-se duma hiperplasia fibrosa inflamatória clinicamente compatível com um pólipo fibroepitelial. A doente foi seguida posteriormente em consulta, onde foi confecionada uma nova prótese total superior, não tendo tido recorrência da lesão desde então. Discussão e conclusões: O pólipo fibroepitelial (ou leaf-like fibroma) induzido por prótese é um tipo de hiperplasia fibrosa provocada por próteses pouco comum na prática clínica. O seu processo de formação é essencialmente igual à do fibroma traumático, sendo que neste caso a sua etiologia é claramente identificável com próteses desajustadas. A evicção prolongada da prótese pode contribuir para a diminuição da dimensão da lesão mas, dada presença relativamente permanente de tecido hiperplásico, a excisão cirúrgica costuma ser necessária. O ajuste da prótese ou a confeção duma nova prótese são também fundamentais para evitar recorrências. O presente caso clínico relata uma lesão pouco comum na prática clínica e mostra a importância da revisão periódica das próteses dentárias a fim de evitar o aparecimento de lesões traumáticas deste tipo. http://doi.org/10.24873/j.rpemd.2022.01.877

\#018 Tórus mandibular e a sua abordagem cirúrgica: relato de um caso clínico

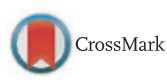

Filipa Veiga*, Paula Maria Leite, Luísa Figueiredo, Cristina Barros, Catarina Machado Ferreira, Luís Sanches Fonseca

Centro Hospitalar Universitáio Lisboa Central

Introdução: O Tórus mandibular é um crescimento ósseo da mandíbula incomum, formado por cortical óssea densa e 